\title{
Progressive Increase of the Mutated Mitochondrial DNA Fraction in Kearns-Sayre Syndrome
}

\author{
NILS-GÖRAN LARSSON, ELISABETH HOLME, BENGT KRISTIANSSON, ANDERS OLDFORS, \\ AND MẢR TULINIUS \\ Departments of Clinical Chemistry [N-G.L., E.H.] and Pathology [A.O.], Gothenburg University, Sahlgrens \\ Hospital, S-413 45 Gothenburg and Departments of Pediatrics [B.K., M.T.], East Hospital \\ S-41685 Gothenburg, Sweden
}

\begin{abstract}
We have performed morphologic and biochemical studies in three pediatric cases of Kearns-Sayre syndrome. All cases had heteroplasmy with a high percentage of mitochondrial DNA (mtDNA) with deletion in muscle. The deletions were mapped to the same region of mtDNA but were of different sizes. The same type of deletion could also be detected in fibroblasts from all cases but the percentage was considerably lower. In two cases, an increase with time of the mutated mtDNA fraction in muscle was found and this increase paralleled the progression of the disease. Oximetric evaluation of respiratorychain function in isolated muscle mitochondria showed a complex I deficiency in one case and was normal in the two other cases. Comparison of the fractional concentration of mtDNA with deletion in muscle and isolated mitochondria showed that the isolated mitochondria were not representative of the mitochondrial population in muscle. Mitochondria with high percentage of mtDNA with deletion were selectively lost. The finding of different mitochondrial populations is in good agreement with the morphology. One case spontaneously recovered from an infantile sideroblastic anemia before the development of Kearns-Sayre syndrome. The anemia was of the same type as that in Pearson's syndrome, a mitochondrial disorder with high amounts of mtDNA with deletion in blood cells. These findings indicate that the phenotype of a mtDNA deletion disorder can change with time and is governed by the fractional concentration of mtDNA with deletion in different tissues. (Pediatr Res 28: 131-136, 1990)
\end{abstract}

\section{Abbreviations}

CT, computed tomography

KSS, Kearns-Sayre syndrome

mtDNA, mitochondrial DNA

After the detection of large deletions of mtDNA in muscle tissue of patients with mitochondrial myopathy (1), the phenotypic expression was soon recognized to be progressive external ophthalmoplegia either alone or as a part of the multisystem

Received December 28, 1989; accepted March 9, 1990.

Correspondence: Dr. Nils-Göran Larsson. Department of Clinical Chemistry, Gothenburg University, Sahlgren's Hospital, S-413 45 Gothenburg, Sweden.

Supported by grants from the Swedish Medical Research Council $(585,7122)$, Linnéa and Josef Carlssons Foundation. Folke Bernadotte Foundation. Sven Jerring Foundation, The Göteborg Medical Society, and Kronprinessan Margaretas Arbetsnämnd för synskadade. syndrome of Kearns-Sayre, which also includes encephalopathy, ataxia, pigmentary retinopathy, and heart block (2-4).

The patients have heteroplasmy with both normal mtDNA and mtDNA with deletion, but the percentage of mtDNA with deletion varies considerably between affected individuals (27$85 \%)$, as does the size of the deletions $(1.3-7.6 \mathrm{~kb})(4)$. The relation between clinical and biochemical dysfunction and quantity and extension of deletions is far from clear. It seems, however, that a high percentage of mtDNA with deletion is a general finding in affected tissues, e.g. muscle and brain, and low or undetectable amounts are found in unaffected tissues, e.g. peripheral blood cells.

A totally different phenotype of a mtDNA deletion disorder is Pearson's syndrome, affecting pancreas, liver, and bone marrow. The patients have a refractory sideroblastic anemia and often succumb in early infancy (5). In this disorder, a high percentage of mtDNA with deletion has been found in peripheral blood cells (6).

Reports on mtDNA deletions have hitherto described percentage, location, extension, and distribution of mutated DNA in different patients. The correlation of the clinical course of the disorder in single patients to changes in percentage or distribution of the mutated DNA has not been studied.

In our report on three patients with KSS, we describe findings at different stages of the disease and present results that indicate that changes in the fractional concentration of mtDNA with deletion parallels the progression of the disease.

\section{CASE REPORTS}

Case 1, M.E. This girl, born in 1977, was the only child of healthy unrelated parents. There was no history of similar disorders in the family. The pregnancy was complicated by antepartum, uterine bleedings. Delivery after premature rupture of the membranes in the 36th gestational week was otherwise uneventful. The birth wt was $2720 \mathrm{~g}$. Early psychomotor development was normal. She attained length and wt corresponding to 2 and 2.5 SD below the reference mean. She had frequent respiratory tract infections during the first year of life. Between the ages of 1.5 and $2.5 \mathrm{y}$, she had diarrhea. Onset of ptosis was between 5 and 6 y of age. Progressive sensorineural hearing loss was diagnosed at 7 y of age, when she also developed concentration and learning difficulties. Clumsiness and balance difficulties were noticed at $8 \mathrm{y}$ of age. At $12 \mathrm{y}$ of age, she had complete ophthalmoplegia, retinal pigmentary degeneration, and dementia. She was atactic with intention tremor and had proximal and distal muscle weakness. She was able to walk without support for $500 \mathrm{~m}$. The gait was slow and unsteady.

Laboratory investigations showed normal serum transaminases and serum electrophoresis. There was an albuminuria of 

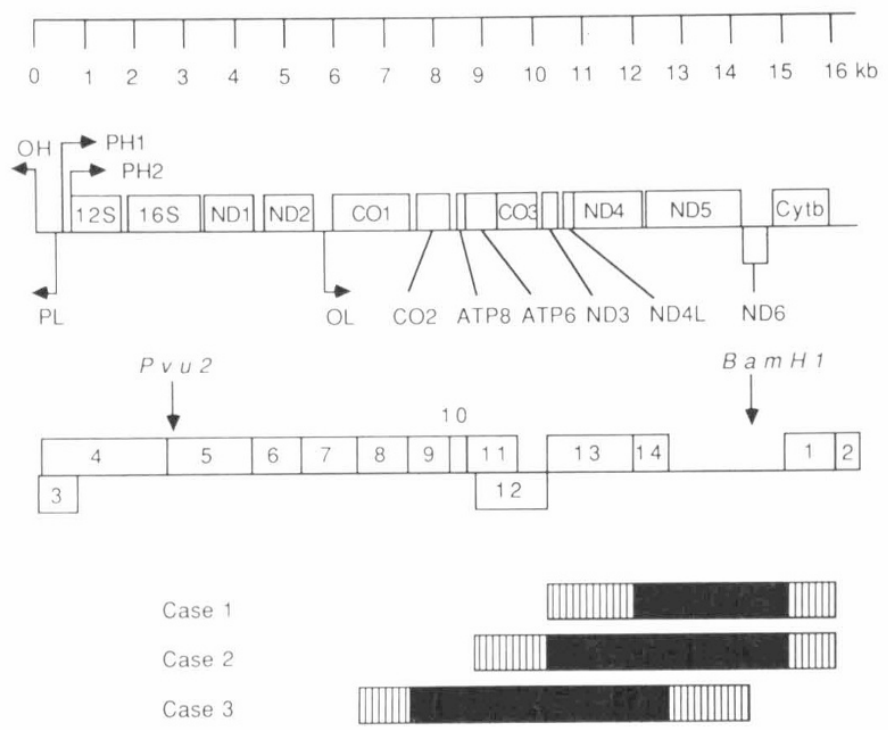

Fig. 1. Linearized map of mtDNA, cloned mtDNA fragments, and location of deletions. The following genes on the heavy and light strands of mtDNA are indicated by hoxes: NADH dehydrogenase (EC 1.6.5.2) subunits $(N D /-6$ and $N D 4 L)$, cytochrome b $(C v t b)$, cytochrome $c$ oxidase (EC 1.9.3.1) subunits 1-3 (COl-3), ATP synthase (EC 3.6.1.34) subunits 6 and 8 (ATP6 and ATP8), and large (I6S) and small (I2S) ribosomal RNA. Transfer RNA genes are not shown. The arrows show the origin of replication for the heavy $(O H)$ and light $(O L)$ strand and the promoters for transcription of the heavy ( $\mathrm{PHI}$ and $\mathrm{PH}$ ) and light $(P L)$ strand. Numbered boxes $1-14$ indicate cloned mtDNA fragments. The fragments correspond to the following sequences according to Anderson et al. (8): I (14956-16053); 2 (15591-16569); 3 (1-740); 4 (412578): 5 (2578-4122); $6(4122-5274) ; 7(5275-6204) ; 8$ (6204-7441); 9 (7441-8287); 10 (8287-8592); 11 (8592-9648); 12 (8729-10254); 13 (10254-11922), and 14 (11922-12640). Arrows indicate the restriction enzyme sites for PvuII (Pvu2) (2650) and BamHI (BamHl) (14258). The locations of mtDNA deletions in cases 1-3 are shown. Filled boxes indicate deleted sequences and hatched boxes indicate areas of uncertainty.

$0.45 \mathrm{~g} / \mathrm{L}$ but no tubular proteinuria. Blood $\mathrm{Hb}$ concentration was $132 \mathrm{~g} / \mathrm{L}$, leukocyte count was $4.7 \times 10^{9} / \mathrm{L}$, and thrombocyte count was $191 \times 10^{9} / \mathrm{L}$. The cerebrospinal fluid protein was increased to $993 \mathrm{mg} / \mathrm{L}$ (reference interval 150-300 mg/L). Blood lactate concentration was intermittently increased up to 3.0 $\mathrm{mmol} / \mathrm{L}$.

ECG showed complete right bundle branch block. CT of the brain showed cerebellar atrophy.

Case 2, L.O.E. This boy, born in 1968, was the second son of healthy, unrelated parents. His older brother was healthy. There was no history of similar disorders in the family. The pregnancy and delivery were uncomplicated. The birth wt was $2450 \mathrm{~g}$. He was healthy and developed normally until about $7 \mathrm{y}$ of age. At school, learning difficulties were noticed, and he was transferred to a special class.

At 8 y of age, he developed ptosis. Vision and hearing loss were detected 2 y later. At 12 y of age, the first signs of ataxia appeared. Muscular weakness was first noticed at $14 \mathrm{y}$ of age. The muscular wasting and weakness progressed gradually. At 17 y of age, the patient was severely disabled with bilateral ptosis, total ophthalmoplegia, retinal pigmentary degeneration, dementia, and severe ataxia. He could not walk without support.

Laboratory investigation at $17 \mathrm{y}$ of age showed a slight increase in serum transaminases [S-aspartate aminotransferase (EC 2.6.1.1) $0.8 \mu \mathrm{kat} / \mathrm{L}$, reference interval $<0.7 \mu \mathrm{kat} / \mathrm{L}, \mathrm{S}$-alanine aminotransferase (EC 2.6.1.2) $1.1 \mu \mathrm{kat} / \mathrm{L}$, reference interval $<0.7]$. Serum electrophoresis was normal and there was no proteinuria. Blood $\mathrm{Hb}$ concentration was $156 \mathrm{~g} / \mathrm{L}$, leukocyte count was $6.5 \times 10^{9} / \mathrm{L}$, and thrombocyte count was $275 \times 10^{9} /$
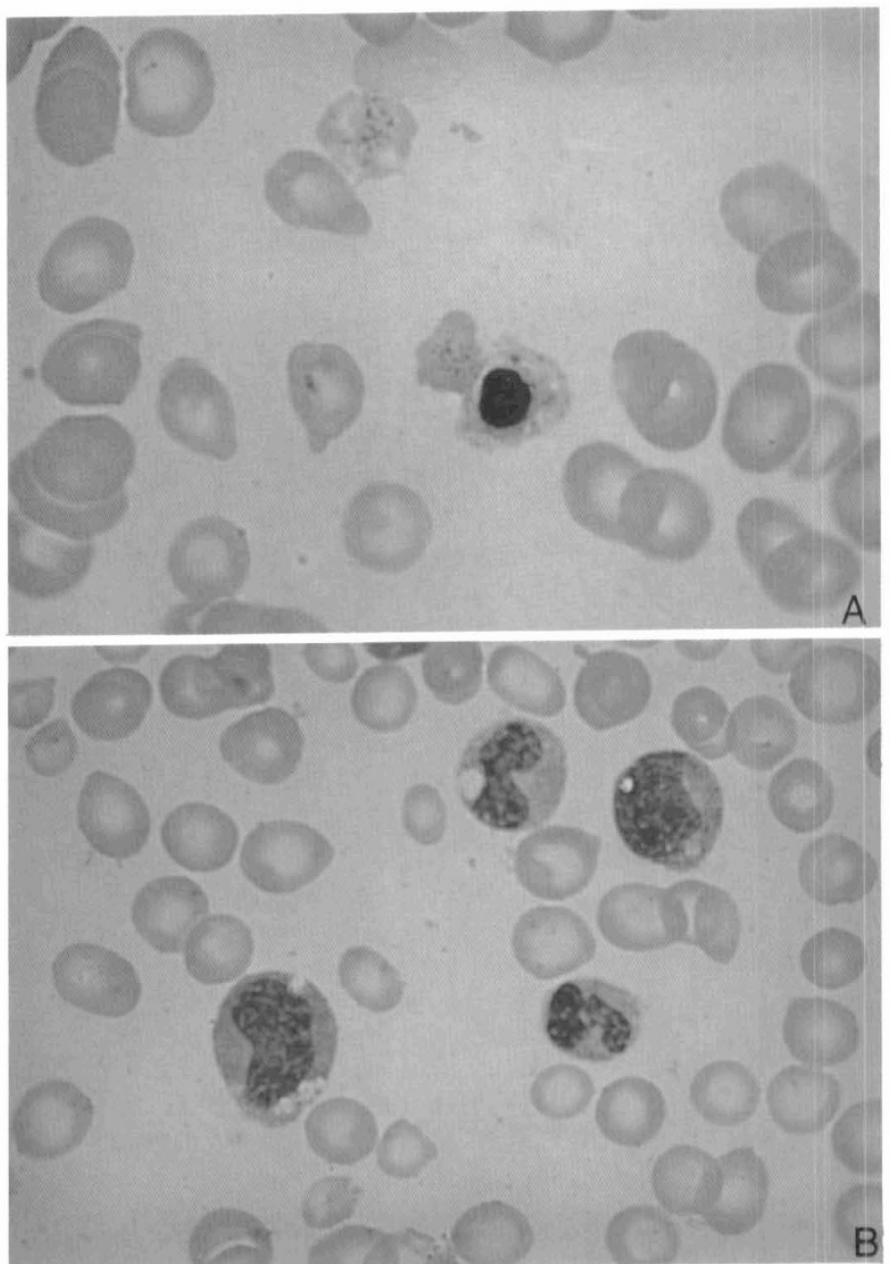

Fig. 2. May-Grünewald-Giemsa stained bone marrow smear from case 3 obtained at 6 mo of age showing dimorphic erythrocytes with increased aniscytosis and an orthocromatic erythroblast with uneven hemoglobinization and Pappenheim bodies $(A)$ and vacuolized myeloid precursor cells $(B)$.

L. The cerebrospinal fluid protein concentration was increased (750 mg/L, reference interval $150-300 \mathrm{mg} / \mathrm{L}$ ). Blood lactate concentration was increased intermittently up to $3.3 \mathrm{mmol} / \mathrm{L}$.

ECG showed atrioventricular block type II. CT of the brain showed general cortical and cerebellar atrophy and areas of low attenuation in the basal ganglia.

The boy died at $19 \mathrm{y}$ of age from cardiorespiratory failure.

Case 3, E.K. This girl, born in 1970 , was the fourth child of healthy, unrelated parents. She and her parents had normal karyotypes. The oldest sister had Turner's syndrome with a $45 \mathrm{X} 0$ karyotype. She had a congenital heart defect and died at the age of $13 \mathrm{~d}$. The second sister was healthy. The third sister had Down's syndrome with trisomy 21 . The pregnancy and delivery were uneventful. The birth wt was $3600 \mathrm{~g}$. Early psychomotor and language development was normal.

At 6 mo of age, a macrocytic (mean corpuscular volume, 113 $\mathrm{fL}$ ) anemia was diagnosed (Hb concentration 63-69 g/L). A marrow smear from this time has been reexamined (see below). At $11 \mathrm{mo}$ of age, the lowest $\mathrm{Hb}$ concentration, $56 \mathrm{~g} / \mathrm{L}$, was found. After that, there was a gradual recovery to $118 \mathrm{~g} / \mathrm{L}$ at $2 \mathrm{y}$ of age with normalization of the erythrocyte indices. There was also a leukopenia and thrombocytopenia with a minimal count of neutrophile leukocytes $\left(0.30 \times 10^{9} / \mathrm{L}\right)$ and thrombocytes $(72 \times$ $10^{9} / \mathrm{L}$ ) at $20 \mathrm{mo}$ of age. Since $4 \mathrm{y}$ of age, the leukocyte count has been normal but the thrombocyte count has been at a slightly subnormal level. A marrow smear at $4 \mathrm{y}$ of age was considered normal except for vacuolization of megakaryocytes.

From the beginning of school at $7 \mathrm{y}$ of age, she had concentra- 


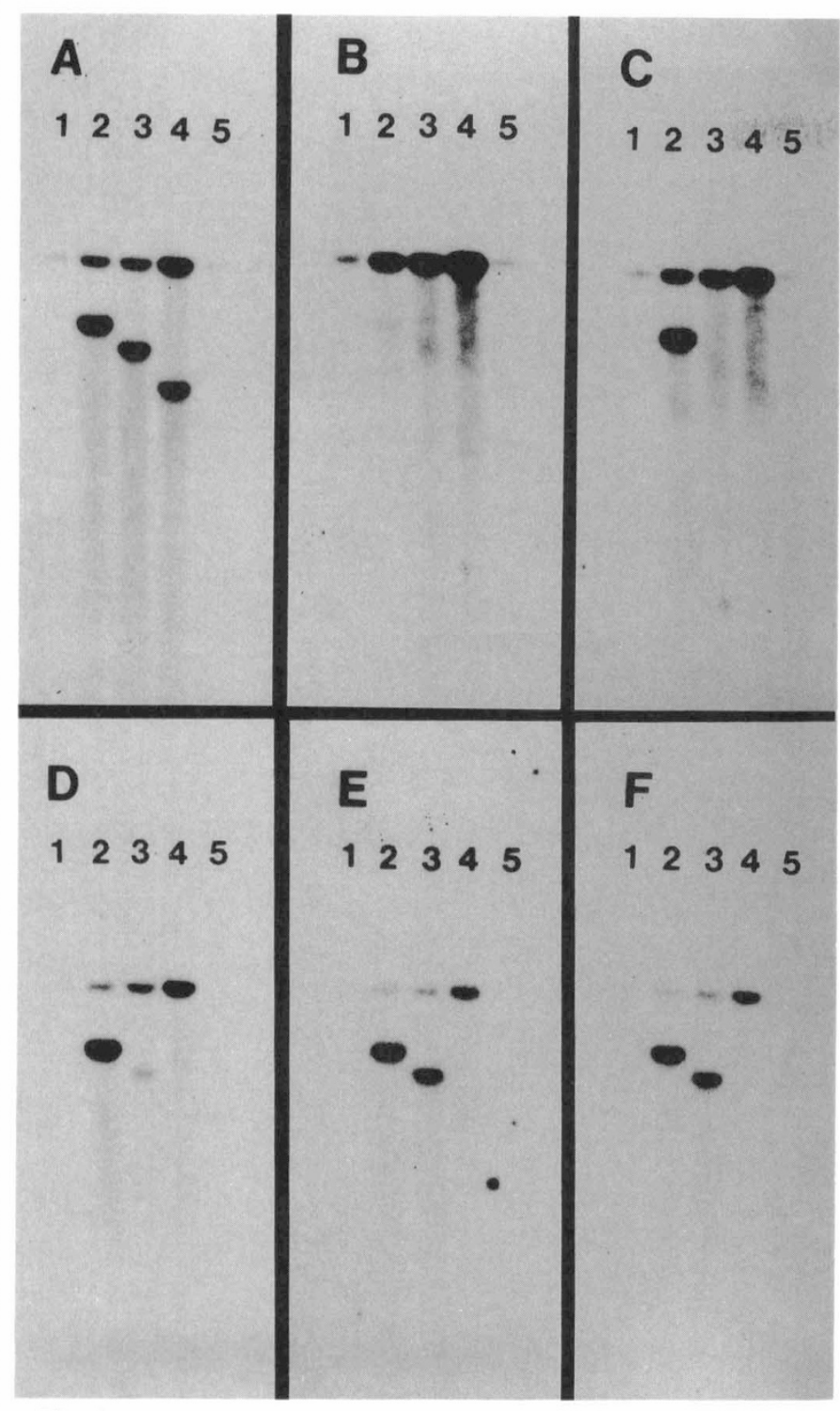

Fig. 3. Mapping of deletions by reprobing the same filter with different cloned mtDNA fragments. Aliquots of $1 \mu \mathrm{g}$ DNA were cleaved with $P v u I I$ and separated in $0.5 \%$ agarose. The autoradiograms show lymphocyte DNA from controls (lanes $I$ and 5) and muscle DNA from cases 1-3 (lanes 2-4). The upper hands correspond to the full length mtDNA of $16.6 \mathrm{~kb}$. The lower bands correspond to deleted mtDNA of $11.7 \mathrm{~kb}$ (lane 2), $10.5 \mathrm{~kb}$ (lane 3), and $9.0 \mathrm{~kb}$ (lane 4). The probe used in panel $A$ was an equimolar mixture of mtDNA fragments 3-14 and in panels $B-F$, the mtDNA fragments $14,13,12,10$, and 9 , respectively. The different cloned mtDNA fragments are shown in Figure 1.

tion and learning difficulties. At 8 y of age, her gait became unsteady and staggering. At 9 y of age, there was deterioration of vision with retinal pigmentary degeneration. At this time, she developed left-side ptosis. She was atactic with intention tremor. By 13 y, she was severely atactic and could not walk. Increasing muscular weakness was noticed and hearing began to deteriorate. A progressive sensorineural hearing loss was diagnosed. At $14 \mathrm{y}$, a pacemaker was implanted due to atrio-ventricular block type III. At 16 y of age, she could no longer stand without support and 2 y later she was completely bedridden. She had severe bilateral ptosis and complete ophthalmoplegia, and had developed spasticity in the lower extremities with increased peripheral reflexes and bilateral Babinski's reflexes.

Laboratory investigation at 19 y of age showed normal serum transaminases. Serum electrophoresis was normal and there was no proteinuria. Blood $\mathrm{Hb}$ concentration was $118 \mathrm{~g} / \mathrm{L}$ and the mean corpuscular volume was $91 \mathrm{fL}$. The leukocyte count was
$5.6 \times 10^{9} / \mathrm{L}$ with a normal differential count. The thrombocyte count was $138 \times 10^{9} / \mathrm{L}$. The blood lactate concentration was intermittently increased up to $3.0 \mathrm{mmol} / \mathrm{L}$.

CT of the brain showed cortical and cerebellar atrophy and symmetrical cystic cavities in the medial parts of pallidum.

\section{MATERIALS AND METHODS}

Materials. Restriction enzymes were obtained from Boehringer Mannheim, Bromma, Sweden and New England Biolabs, Beverly, MA. All enzymes, the plasmids, and the primer used in the cloning procedures were from Pharmacia, Uppsala, Sweden.

Muscle biopsies. In all cases, open muscle biopsies were obtained from the vastus lateralis muscle under general anesthesia after informed consent of the parents. The control biopsies were from children who underwent muscle biopsy either because of an orthopedic operation giving access to the vastus lateralis muscle or because of suspected neuromuscular disease of nonmitochondrial origin.

In case 1 (M.E.), a muscle biopsy was done at 12 y of age. In case 2 (L.O.E.), muscle biopsies were done at 14, 16, and $17 \mathrm{y}$ of age. In case 3 (E.K.), muscle biopsies were done at 14 and 19 y of age. mtDNA analysis was done on all biopsies. Enzymehistochemical analysis was done on all biopsies except the first one of case 2. The respiratory-chain function in isolated mitochondria was analyzed in the last biopsy of each case.

Our study is part of a study on mitochondrial disorders in children which is approved by the Ethical Committee of the Medical Faculty, Gothenburg University.

Morphology. Muscle biopsies. Cryostat sections were incubated for succinate dehydrogenase and cytochrome $c$ oxidase (7). The proportion of ragged red fibers and fibers totally lacking cytochrome $c$ oxidase activity were estimated by counting all muscle fibers in one muscle fascicle, which includes some 200 muscle fibers.

Bone marrow. A part of the original May-Grünewald-Giemsa stained slide from case 3 taken at 6 mo of age was destained by methanol and restained for iron with Prussian blue.

Biochemistry. Fibroblasts. Fibroblasts were grown from skin biopsies taken at $12 \mathrm{y}$ of age (case 1), at $15 \mathrm{y}$ of age (case 2), and at $19 \mathrm{y}$ of age (case 3 ) in Eagle's minimum essential medium with $9 \%$ FCS. The mtDNA analyses were done after 6-10 passages.

Respiratory chain function in mitochondria. Oximetry was performed on freshly isolated muscle mitochondria, as previously described (7).

$m t D N A$-analysis. Probes. Fourteen different human mtDNA fragments in single-stranded M13 vectors were generously provided by Dr. M. King and Professor G. Attardi of the California Institute of Technology, Pasadena, California. The fragments are shown in Figure 1 and indicated by numbered boxes $1-14$. They correspond to nucleotide $1-12640$ and 14956-16569, according to Anderson et al. (8). The fragments were transferred to doublestranded plasmids to simplify the procedures for amplification and purification of the mitochondrial fragments. The fragments 3-14 were converted to double-stranded DNA by one of the following procedures and then transferred to the plasmids pT218R and/or pTZ19R. The double-stranded replicative forms of M13 vectors containing fragments $4,5,8,9,10,11$, and 14 were obtained by transforming TG1 bacteria. M13 vectors containing fragments $3,6,7,12$, and 13 were converted to doublestranded DNA with T4 DNA polymerase, gene 32 protein, and the M13 universal sequencing primer (9). The fragments 3-14 were obtained by restriction enzyme digestion of the doublestranded M13 vectors. The fragments were isolated and transferred to the plasmids pTZ18R and/or pTZ19R by using standard procedures (10). The plasmids were amplified in $\mathrm{HB} 101$ bacteria (10). The fragments were then purified from the plasmids (10) and used to prepare radioactive probes by the random priming method $(11,12)$. 


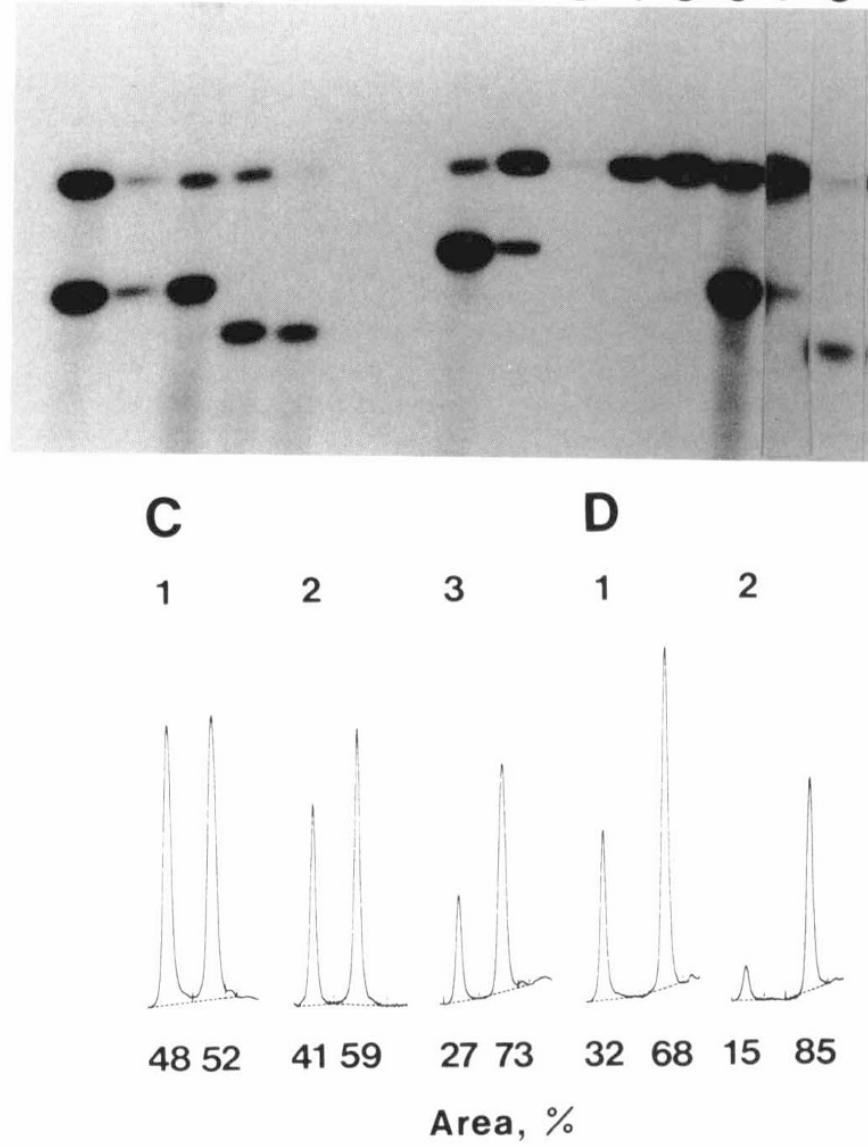

Fig. 4. Quantitation of the fraction of mtDNA with deletion. Aliquots of $0.5 \mu \mathrm{g}$ DNA were cleaved with $P v u I I$, separated in $0.5 \%$ agarose, and transferred to a Hybond $\mathrm{C}$ extra filter. The cloned mtDNA fragment 5 was used as the probe. The upper bands correspond to the full length mtDNA of $16.6 \mathrm{~kb}$. The lower bands correspond to the deleted mtDNA of $11.7 \mathrm{~kb}$ (panel B, lanes 1 and 2), $10.5 \mathrm{~kb}$ (panel A, lanes $1-3$ and panel B, lanes 6 and 7), and $9.0 \mathrm{~kb}$ (panel $A$, lanes 4 and 5 and panel B, lanes 8 and 9). Panel $A$ of the autoradiogram shows muscle DNA from case 2 obtained at 14, 16. and $17 \mathrm{y}$ of age (lanes 1-3) and from case 3 at 14 and $19 \mathrm{y}$ of age (lanes 4 and 5). Panel B of the autoradiogram shows muscle DNA (lanes 1,6 , and 8 ) and fibroblast DNA (lanes 2, 7, and 9) from cases 1-3, respectively. Lymphocyte DNA from case 1 (lane 3) and her parents (lanes 4 and 5) are also shown. The autoradiogram in panels $A$ and $B$ was obtained after $6 \mathrm{~h}$ exposure except for lanes 7 and 9 in panel $B$, which show an exposure for $24 \mathrm{~h}$. Panels $C$ and $D$ show a densitometric scanning of the autoradiogram obtained after $3 \mathrm{~h}$ exposure of the same blot as in panel $A$. The fractions of normal and deleted mtDNA are indicated by the first and second peak, respectively. The relative amount of each peak is shown in percent. Panel $C$ (recordings $1-3$ ) shows the result of the scanning of lanes $1-3$ in panel A, and panel $D$ (recordings 1 and 2 ) shows the result of the scanning of lanes 4 and 5 in panel $A$, respectively.

The radioactive probes for fragments 1 and 2 were made using the original M13 single-stranded DNA as template.

DNA extraction. DNA was extracted from 5-50 mg of frozen muscle. The muscle tissue was pulverized in liquid nitrogen in a mortar. The finely ground powder was incubated in $500 \mu \mathrm{L}$ Tris $\mathrm{HCl} 10 \mathrm{mmol} / \mathrm{L} \mathrm{pH} 7.5$, EDTA $50 \mathrm{mmol} / \mathrm{L}$, SDS $1 \%$, and proteinase $\mathrm{K} 1 \mathrm{mg} / \mathrm{mL}$ at $50^{\circ} \mathrm{C}$ for $6-8 \mathrm{~h}$. The solution was then extracted once with phenol saturated with water and twice with phenol:chloroform $(1: 1, \mathrm{vol} / \mathrm{vol})$. The DNA was precipitated with ethanol. The precipitate was dissolved in Tris $\mathrm{HCl} 10 \mathrm{mmol} /$ $\mathrm{L} \mathrm{pH} \mathrm{7.5,} \mathrm{with} \mathrm{EDTA} 1 \mathrm{mmol} / \mathrm{L}$. About $1 \mu \mathrm{g} \mathrm{DNA} / \mathrm{mg}$ tissue was obtained. A similar procedure was used to prepare DNA from leukocytes and fibroblasts.

Restriction enzyme analysis. Aliquots of $0.5-1 \mu \mathrm{g}$ DNA were cleaved with the restriction enzymes PvuII, HindIII, BamHI, EcoRI, or SnaBI and separated by electrophoresis in $0.5 \%$ agarose. The DNA was then transferred to Hybond $\mathrm{C}$ extra filters (Amersham, Solna, Sweden) by capillary blotting in $\mathrm{NaCl} 3 \mathrm{~mol} /$ $\mathrm{L}$, sodium citrate $0.3 \mathrm{~mol} / \mathrm{L}$ as described (10). Filters were baked for $6 \mathrm{~h}$ at $80^{\circ} \mathrm{C}$ and hybridized and washed under standard conditions (10). Kodak X-Omat S films were exposed for 2-6 h.
Densitometric scanning. Autoradiograms were scanned in a CS-9000 densitometric scanner (Shimadzu, Kyoto, Japan). The absorption-transmission mode was used. The wavelength was $600 \mathrm{~nm}$ and the zig-zag scanning mode, which gives a beam size of $0.4 \times 0.4 \mathrm{~mm}$, was used. The swing width was $2 \mathrm{~mm}$. Autoradiograms were exposed to be in the linear range of the $x$ ray film. To quantitate mtDNA with deletion, autoradiograms from three different blots were scanned, except for biopsy 2 in case 2, and the mitochondrial preparations, where there was insufficient material for multiple analysis.

\section{RESULTS}

Morphology. Muscle biopsies. Ragged red fibers were found in all biopsies and the amount varied between 0.8 and $1.5 \%$. No significant increase with time was found. All ragged red fibers were cytochrome $c$ oxidase negative. Case 1 had a general high activity of cytochrome $c$ oxidase. Only the ragged red fibers were negative. In both biopsies from case $2,5 \%$ of the fibers were cytochrome $c$ oxidase negative. In case 3 , the cytochrome $c$ oxidase negative fibers were 6 and $11 \%$ in the first and second biopsies. 
Table 1. Oximetric analysis of respiratory-chain function in isolated muscle mitochondria and percentage of miDNA with deletion in whole muscle and isolated mitochondria

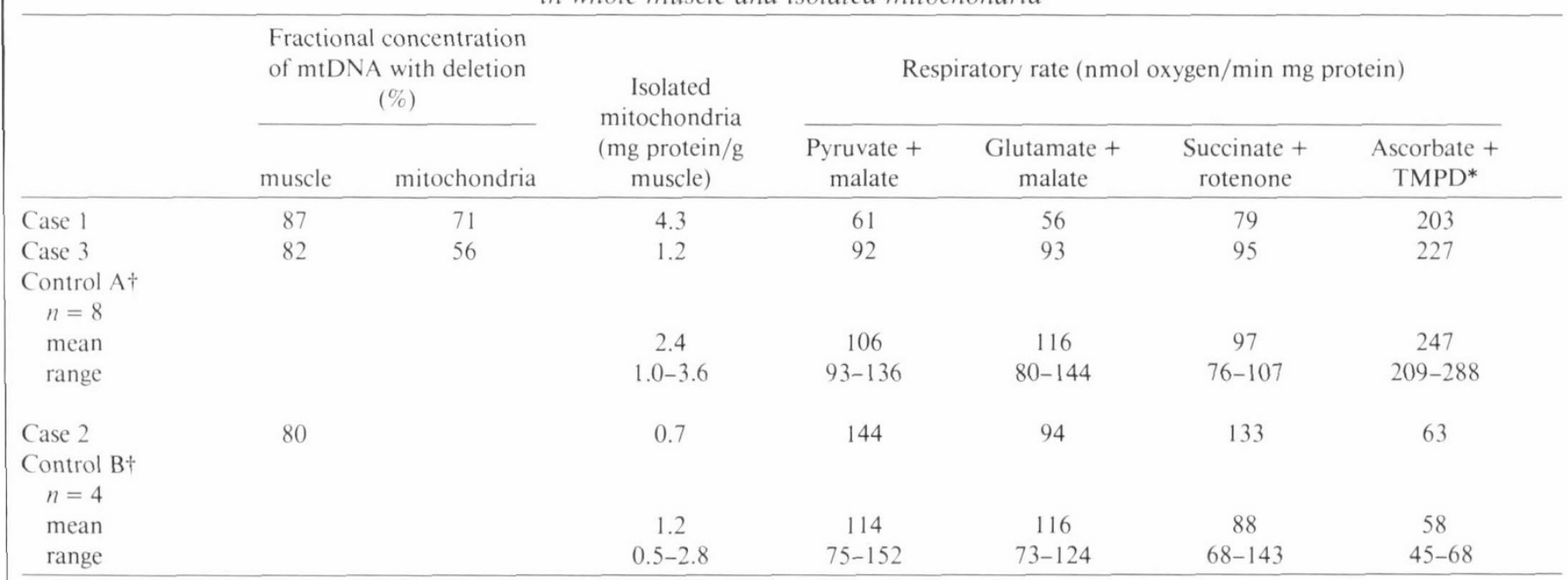

* TMPD, $N, N, N^{\prime}, N^{\prime}$,-tetramethyl-p-phenylenediamine.

† During the study, the TMPD concentration was changed from $60 \mu \mathrm{mol} / \mathrm{L}$ (case 2 and control B) to $500 \mu \mathrm{mol} / \mathrm{L}$ (cases 1 and 3 and control A).

Bone marrow. The erythropoesis was macroblastic in case 3. The erythrocytes showed a dimorphic picture with an increased anisocytosis and poikilocytosis. There was a conspicuous finding of Pappenheim bodies (Fig. 2). Iron staining revealed a heavy load of hemosiderin in erythrocytes and erythroblasts and the presence of ringed sideroblasts. The myeloid precursor cells had a normal degree of maturation and distribution but showed vacuolization (Fig. 2).

Biochemistry. In all three cases, a heteroplasmy with large deletions of mtDNA in muscle was found. The deletions were mapped by reprobing the same filter with different mtDNA fragments as shown in Figure 3, and by using different restriction enzymes. The deletions were $4.9,6.1$, and $7.6 \mathrm{~kb}$ in size. They all affected several protein coding genes and several transfer RNA genes, which are located between the protein genes. The sequences needed for replication and transcription of the mtDNA genome were not affected. The locations of the deletions are shown in Figure 1.

To estimate the molar ratio between full length and deleted mtDNA, the cloned mtDNA fragment 5 was used as a probe. The sequence corresponding to this probe is not affected by the deletions. The relative intensities of the hybridization signals from full length and deleted mtDNA was determined by densitometric scanning of the autoradiogram.

In two cases, muscle biopsies from different time points were available. The fractional concentration of mtDNA with deletion increased over time. Figure 4 ( panel $A$ ) shows mtDNA in three biopsies from case 2 obtained at the ages of 14, 16, and $17 \mathrm{y}$ and two biopsies obtained at the ages of 14 and 19 y from case 3 . Densitometric scanning of autoradiograms from different blots showed that in case 2 the mean amount of mtDNA with deletion increased from 52 (range 48-55) to 59 and finally to 80 (73$85) \%$. In case 3 , the mean amount increased from $60(56-68)$ to $82(78-85) \%$. Recordings from densitometric scannings are shown in Figure 4 ( panels $C$ and $D$ ).

The percentage of mtDNA with deletion was considerably lower in fibroblasts than in muscle in all three cases (Fig. 4, panel $B$ ). No deletion could be detected in lymphocytes from case 1 and her parents even after prolonged exposures (Fig. 4, panel B).

Oximetric analysis of the respiratory chain function in isolated muscle mitochondria from all cases is shown in Table 1. A reduced complex I activity was found in case 1 . The other two patients had normal respiratory rates.

To investigate if the mitochondrial preparations were representative of the mitochondrial population in muscle, the percentage of mtDNA with deletion was measured in both mito- chondrial and whole muscle preparations (Table 1). A lower percentage of mutated mtDNA was found in the mitochondrial preparations. The fraction of normal mtDNA in the mitochondrial preparation was more than twice that in whole muscle in case 3 , indicating that the preparation procedure selected against deficient mitochondria.

\section{DISCUSSION}

We have found a progressive increase in the percentage of mtDNA with deletion that parallels the progressive clinical course. Only small variations in the percentage of mtDNA with deletion have been found when multiple autopsy samples from the same tissue have been compared (13). It is thus likely that the increase in percentage of mtDNA with deletion in our cases is real and not due to sampling errors.

The histochemical analysis of muscle in our and other patients $(13,14)$ has shown lack of cytochrome $c$ oxidase staining in some fibers but not in others. This uneven distribution between fibers in combination with the rather wide reference intervals for the different respiratory-chain enzymes may contribute to the variable results obtained in studies of the respiratory-chain enzymes in cases of $\operatorname{KSS}(3,4)$. Oximetric measurements on isolated muscle mitochondria are the most accurate methods for assessing respiratory-chain function in vitro. When there is a heterogenous population of mitochondria, which is the case in KSS as evidenced by the histochemical findings, the question arises as to whether the mitochondrial preparation is a representative sample of the total mitochondrial population. Comparison of the percentage of mtDNA with deletion between whole muscle and isolated mitochondria shows not only that there is an uneven distribution of mtDNA with deletion between mitochondria but also that the mitochondria with the highest percentage of deletion are selectively lost in the preparation procedure. This indicates that the mitochondria with the highest percentage of mtDNA with deletion are the most deranged mitochondria, probably not only with regard to physical properties, but also with regard to the respiratory-chain function.

Although the deletions in our patients affect different parts of the mtDNA, they all affect several transfer RNA genes. The high percentage of mtDNA with deletion and the uneven distribution of deleted genomes probably causes a deficiency of several specific transfer RNA in the most affected mitochondria. This deficiency might at a certain level limit mitochondrial translation and lead to a general deficiency of all mtDNA encoded proteins. A transfer RNA deficiency might explain why the phenotypes of 
the patients are similar although the deletions are of different sizes and locations.

In case 1, considerable muscular function was maintained despite the fact that the percentage of mtDNA with deletion was $87 \%$ in muscle. Although a high frequency of muscle fibers with negative cytochrome $c$ oxidase staining is common in KSS, it was not seen in this case, except in the sparse ragged red fibers. Mitochondria with a high percentage of affected mtDNA was included in the mitochondrial preparation of this patient and a complex I deficiency was found. The deletion in this case affected at least two NADH-dehydrogenase subunits and no cytochrome $c$ oxidase subunits. These findings indicate that transfer RNA complementation occurs in this case and that a deletion can cause deficiency of specific gene products.

In clonal cultures of fibroblasts from patients with KSS, both normal and heteroplasmic clones have been found. The normal cells divided more rapidly than the heteroplasmic cells, which probably was the reason for the observed selection against cells with mtDNA with deletion in uncloned cell cultures (15). The sideroblastic anemia of case 3 was of the same type as that of Pearson's syndrome. It is likely that this patient during early childhood had a high percentage of mtDNA with deletion in blood cells. The spontaneous recovery indicates that selection favoring normal cells occurs in vivo. The mechanism for selection favoring mtDNA with detetion in muscle fibers is unclear but might be related to an increased mitochondrial proliferation in response to deficient energy production.

Acknowledgments. The authors thank Prof. B. Hagberg for help in management of the patients, Per Elias, Ph.D. for valuable advice concerning the cloning procedures, Dr. Brigitta Swolin for morphologic evaluation of bone marrow smears, Dr. M. King and Professor G. Attardi for the generous gift of human M13 mtDNA clones, and S. Shanske and E. Schon for communicating results before publication.

\section{REFERENCES}

1. Holt JJ, Harding AE, Morgan-Hughes JA 1988 Deletions of muscle mitochondrial DNA in patients with mitochondrial myopathies. Nature 331:717-719
2. Lestienne P, Ponsot G 1988 Kearns-Sayre syndrome with muscle mitochondrial DNA deletion. [letter] Lancet 1:885

3. Zeviani M, Moraes CT, DiMauro S, Nakase H. Bonilla E, Schon EA, Rowland LP 1988 Deletions of mitochondrial DNA in Kearns-Sayre syndrome. Neurology 38:1339-1346

4. Moraes CT, DiMauro S, Zeviani M, Lombes A. Shanske S, Miranda AF. Nakase H, Bonilla E, Werneck LC, Servidei S, Nonaka I, Koga Y, Spiro AJ, Brownell KW, Schmidt B, Schotland DL, Zupanc M, DeVivo DC, Schon EA, Rowland LP 1989 Mitochondrial DNA deletions in progressive external ophthalmoplegia and Kearns-Sayre syndrome. N Engl J Med 320:12931299

5. Pearson HA, Lobel JS, Kocoshis SA, Naiman JL, Windmiller J, Lammi AT, Hoffman R, Marsh JC 1979 A new syndrome of refractory sideroblastic anemia with vacuolization of marrow precursors and exocrine pancreatic dysfunction. J Pediatr 95:976-984

6. Rotig A, Colonna M, Bonnefont JP, Blanche S, Fischer A, Saudubray JM, Munnich A 1989 Mitochondrial DNA deletion in Pearson's marrow/pancreas syndrome. Lancet 1:902-903

7. Oldfors A. Sommerland H, Holme E, Tulinius M. Kristiansson B 1989 Cytochrome $c$ oxidase deficiency in infancy. Acta Neuropathol (Berl) 77:267-275

8. Anderson S, Bankier AT, Barrell BG, de Bruijn MHL, Coulson AR, Drouin J, Eperon IC, Nierlich DP, Roe BA, Sanger F, Schreier PH, Smith AJH, Staden R. Young IG 1981 Sequence and organization of the human mitochondrial genome. Nature 290:457-465

9. Craik CS, Largman C, Flescher T, Roczniak S, Barr PJ, Fletterick R, Rutter WJ 1985 Redesigning trypsin: alteration of substrate specificity. Science 228:291-297

10. Ausubel FM, Brent R, Kingston RE, Moore DD. Seidman JG, Smith JA, Struhl K 1989 Current Protocols in Molecular Biology. Wiley \& Sons, New York

11. Feinberg AP, Vogelstein B 1983 A technique for radiolabelling DNA restriction endonuclease fragments to high specific activity. Anal Biochem 132:6-13

12. Feinberg AP, Vogelstein B 1984 Addendum. A technique for radiolabelling DNA restriction endonuclease fragments to high specific activity. Anal Biochem 137:266-267

13. Shanske S, Moraes CT, Lombes A, Miranda AF, Bonilla E, Lewis P. Whelan MA, Ellsworth CA, DiMauro S 1990 Wide-spread tissue distribution of mitochondrial DNA deletions in Kearns-Sayre syndrome. Neurology 40:2428

14. Bresolin N, Moggio M, Bet L, Gallanti A, Prelle A. Nobile-Orazio E, Adobbati L, Ferrante C, Pellegrini G, Scarlato G 1987 Progressive cytochrome c oxidase deficiency in a case of Kearns-Sayre syndrome: morphological, immunological, and biochemical studies in muscle biopsies and autopsy tissues. Ann Neurol 21:564-572

15. Moraes CT, Schon EA, DiMaura S, Miranda AF 1989 Heteroplasmy of mitochondrial genomes in clonal cultures from patients with Kearns-Sayre syndrome. Biochem Biophys Res Commun 160:765-771 